OBETS. Revista de Ciencias Sociales

Vol. 10, n. ${ }^{\circ} 1,2015$, pp. 211-234

ISSN: 1989-1385

DOI: 10.14198/OBETS2015.10.1.08

\title{
RESILIENCE BY SOLIDARY TIES ${ }^{1}$ RESILIENCIA POR LAZOS DE SOLIDARIDAD
}

\author{
Antonio Alaminos \\ Universidad de Alicante, Spain \\ alaminos@ua.es \\ Irina Pervova \\ Saint-Petersburg State University, Russia \\ pervovai@mail.ru
}

\begin{abstract}
Resumen
Tras introducir teóricamente los conceptos de "Benevolencia" (Schwartz), "Lazos de solidaridad" y "Resiliencia", se presenta su operativización en la Encuesta Social Europea de 2012. La hipótesis de partida plantea que la presencia de un valor alto en Benevolencia influye en la participación en interacciones solidarias y que la participación en redes solidarias facilita el recobrarse de las crisis. A partir de estos datos, y considerando varias sociedades europeas, se han testado dos modelos alternativos, según el efecto de la Benevolencia y los lazos de solidaridad sobre la resiliencia. Se concluye que existe un efecto directo de los valores de Benevolencia sobre la Solidaridad, y de esta sobre la Resiliencia. La influencia de los valores de Benevolencia sobre la Resiliencia se establece de forma indirecta mediante la activación de relaciones solidarias.
\end{abstract}

Palabras clave: Benevolencia, Solidaridad, Resiliencia, Modelos estructurales

\section{Abstract}

This article considers an empirical approach to the relationships among three well known concepts: "Benevolence" (Schwartz), Solidarity and Resilience ("Subjective wellbeing scale" - SWB). The first concept refers to cultural values,

${ }^{1}$ This article is integrated in the research program "Civil Engagement in Social Work: Developing Global Models", funded by FP7 UE. PEOPLE-2012-IRSES. Grant Agreement Number 318938. Civil Engagement in Social Work: Developing Global Models (CIVIL-SW). PIRSES-GA-2012-318938 
the second one to social networks and the third to the ability to recover from crisis. The measurement of solidarity has been done from the point of view of supportive ties. The baseline hypothesis considers that the presence of a high value in Benevolence contributes to the involvements in solidarity networks. Participation in supportive relationships facilitates recovery from personal crisis. Using data from the European Social Survey (ESS6), we conclude from this structural analysis that the resilience reflected in a society is partly a consequence of the supportive networks shaped by the presence of benevolence values.

Keywords: Benevolence values, solidarity, resilience, social ties, structural model.

\section{INTRODUCTION}

In the last two-three decades the debates whether Western societies are experiencing an erosion of civic life and declining levels of social trust have grown more and more pronounced (Paxton, 1999, 2002; Putnam, 1995; Quintelier, 2007; van Oorschot, Arts, \& Gelissen, 2006). In a market based consumer oriented society material prosperity is valued for its own sake and does not reflect the historical spiritual ideals which were central to old moral or ethical standards. Due to globalization and marching neoliberalism developing countries are copying the West in many ways; but this duplication may not be in the best interest of their unique societies. Current global social processes put pressure on the individual to cope with significant socio-economic changes and new social structures. This coping (resilience) requires new approaches to challenges which are in a state of flux. Thus it is not easy to develop and maintain resilience in the modern world. Historically man was, is and will be a social being, so help and support to others may be viewed as a basic element of human conscience and social morality.

At the same time a number of theorists suggest that marketization of society on the macro-social level may eventuate in a type of marketization of the mentality of policy makers and the general public. This expansion of the market mentality and indexes may reflect monetary fetishism and bring about moral insensitivity to human values in considering the needs of vulnerable people and social groups. The marketized mentality is a latent construct of generalized cultural orientation on the basis of theoretically relevant individual attitudes and performance repertoires. The degree of commitment to a marketized mentality will be inversely related to the degree of acceptance of solidarity values. The degree of integration in the family, friendship networks, religion and politics will be inversely related to the degree to which a general marketized mentality and solidarity values are expressed (Hövermann et al, 2015). A theoretical model for values change was presented by Bardi and Goodwin (2011). 
The current global social and financial crises affect individual status and behavior with an associated need for compassion for people in need. Without the help of others it is hard for the majority of people to effectively cope with multiple social challenges and personal misfortunes. Thus benevolence and solidarity are the keys for fostering resilience. Benevolence, solidarity and resilience should be basic considerations within the system of social and individual values in responding to the current socio-economic conditions in the world.

Values are shaped by structural and cultural forces and influence individual judgment and behavior. They may unite or divide people and societies. Values are abstract concepts conveying what people consider to be important. Schwartz (1992) proposed ten distinct value types ordered along two dimensions:

(1) Openness to Change (stimulation, self-direction, and hedonism) vs Conservation (tradition and security);

(2) Self-Enhancement (achievement, power, and hedonism) vs Self-Transcendence (universalism and benevolence).

People may differ significantly in the importance of each value, but the structure and hierarchy of value types has found to be universal (Bardi et al, 2009; Schwartz, \& Bardi, 2001; Tulviste, \& Tamm, 2014). Benevolence, selfdirection and universalism have been found to be of prime importance across cultures (Schwartz \& Bardi, 2001; Tulviste \& Tamm, 2014). The understanding of value(s) interconnections and interactions helps in predicting social attitudes, behaviors and experiences.

The extant research literature does not provide a centralizing theory or conceptual framework for defining and describing the relationships among the basic concepts of benevolence, solidarity and resilience. The current discussion is intended to provide a frame of referenced research for illustrating these interrelated elements affecting the coping capacities of people within crisis situations or social and economic change processes.

Empathy and compassion are for more constructive than pity. Access, acceptance, respect and support are qualitatively different from the usual definitions of charity. The combined effects of such values as benevolence, solidarity and resilience constitute the fundamental base for nurturing the social capital and networks underlying life supports and opportunities for people.

\section{Benevolence}

Benevolence has been considered as a critical element of individual character and social cohesion since the earliest civilizations. Both Confucius and Goethe 
agreed that "good will" was one of three necessary traits for man. Thus mutual value and reciprocity in relationships are fundamental to sharing which respects the dignity and rights of the all involved.

The history of benevolence has also demonstrated that it can deteriorate to levels of devaluation and patronization. This point is emphasized in the retrospective analysis of the role of benevolence among middle-class women of the 19th and 20th centuries in America (Knight, 1997), focusing on the ethics of benevolence and the ethics of justice.

According to Schwartz (1992) benevolence is the preservation and enhancement of the welfare of people with whom one is in frequent personal contact (helpful, honest, forgiving, loyal, and responsible). The centrality of social support for good interpersonal relationships is well discussed in literature, but in the last two decades the importance for an individual to support others is highly emphasized (Brown et al, 2003; Diener, \& Seligman, 2002; Dunn et al, 2008; Helliwell, \& Putnam 2005; Huppert et al, 2013).

Social and individual values are considered central to true benevolence. Schwartz (1992) defines values as abstract goals that serve as guiding principles and confirms that benevolence values are the most important factor for most people in most societies.

An investigation of the relationship between personal values and life satisfaction among twenty-five (25) European countries was reported by Sortheix and Lonnqvist (2014). The Human Development Index (HDI) was used as a contextual moderator. The results of the study included: (1) high levels of benevolence (and hedonism) were correlated with high levels of Life Satisfaction (LS); (2) Higher power and security values were associated with lower life satisfaction levels; achievement values were higher in low LS countries but lower in high LS nations; and (4) universalism values portrayed an opposite pattern to achievement values.

Charitable giving (benevolent donations) is an important aspect of the economics of services to vulnerable people. It is estimated that this benevolent giving represents a 300 billion dollar a year "industry" (Aretz \& Kube 2013). People able to designate the recipient(s) of the funding tend to donate larger amounts. This may suggest that the ability to decide who is worthy of support is an important variable.

The area of corporate social responsibility has been of significant interest due to the combined effects of neo-liberal models and the trends to privatized free-market status for human services (Malsch, 2013). An analysis of the impact of family control on stakeholders' perceptions of benevolence considered benevolence as an element of a trustworthiness construct (Hauswald, \& Hack, 2013). 
An assessment of relationships between benevolence and honesty indicated that prosocial lying (lying with the intent to help or benefit someone) is judged to more moral than telling the truth (Levine \& Schweitzer, 2014). Both honesty and benevolence are considered to be important elements of a moral character; but when the two conflict benevolence will be judged more important.

For Adam Smith, the moral superiority of benevolence is paramount for man. "The wise and virtuous man is at all times willing that his own private interest should be sacrificed to the public interest of his own particular order of society. He is at all times willing, too, that the interest of this order or society should be sacrificed to the greater interest of the state or sovereignty, of which it is only a subordinate part" (Smith, 1982, 235).

\section{Solidarity}

Social connectedness, according to scholars is linked to positive levels of happiness and satisfaction, health and productivity (Helliwell \& Putnam, 2005; Huppert et al, 2013; Putnam, 2000). Solidarity in both concept and application has been the focus of a wide range of researchers during recent decades; particularly since the early work of Durkheim. However, solidarity viewed as social networks promoting reciprocity and caring relationships has been a matter of concern for social theorists, religious thinkers and philosophers for thousands of years. Much of this inquiry considered the elements of ethics and morality as fundamental to the basic processes of developing social cohesion. Shankara, an early Hindu philosopher, assumed that morality was basically the awareness that life should be lived with the sense that there is a union among all living things; centuries later Kant, a noted German philosopher propounded the concept of an absolute moral law (a type of categorical imperative), while a countryman Nietzsche postulated that compassion was a contrivance of Christianity and the "Ubermensch" (supermen exhibiting a will for power) were above all ordinary morality. The dialogue regarding the role of morality in social cohesion is continuing (Bauman, 1993; Gallagher, 2013).

The range of applications of the basic principles of solidarity to socio-political issues or interests includes areas such as: influence on the planning and development of social welfare services (Houtepen \& Ter Munen 2000); integration among European countries (Stevenson 2006); dynamics of processes involved in democratic governance (Putnam 1994); development of global democratic processes (Brunkhorst, 2009); and factors affecting loyalty and allegiance to particular religions, ethnic groups or nations (Betz \& Johnson 2004). Chief governmental officers in the European Union (EU), e.g., Germany, voice concerns regarding economic solidarity. On a broader front, the development 
of helping relationships related to ecological considerations was discussed (Rock \& Degeling, 2014). A common assumption appears to be that the principles of solidarity apply to a broad array of social and political problems or issues.

The issues and concerns regarding the intensive and pervasive effects of Information and Communication Technology (ICT) on social networks, social networking and inter-personal bonding has been examined by a number of authors (Eyre, \& Littleton, 2012; Firat, 2014; Schroeder, \& Ling, 2013).

Current concepts of solidarity as processes which lead to or solidify social bonds are discussed by a number of researchers. Solidarity is discussed as the result of relationships between philosophical concepts of liberty and metaphysical concepts of loyalty. Four types of solidarity are proposed from an enlightenment perspective: (1) self-centered solidarity: freedom from intrusion by others and supported by legalistic provisions; (2) Anglo-Saxon reflexive solidarity: a primary focus is on mutual understanding and empathy for others; (3) continental solidarity: subordinates the role of empathy and emotion, and places major stress on rational argument and reason; (4) recognitive solidarity: introduces reciprocity as a primary consideration (Kappeller, \& Wolkenstein, 2013).

Investigation of the implications of socio-economic change on the building of bonds for solidarity shows these bonds as fundamental to cooperation and collective action, especially in conditions of economic trauma or natural disasters (Carpenter, 2014; Forno, \& Graziano, 2014) and within the framework of intergenerational relations (Hodgkin, 2014).

These types of investigations confirm the role of solidarity in basic human networking and interactions. The connection of solidarity and resilience is the focus of discussions on social exclusion, right to education, gender bias and discrimination (Hlatshwayo, \& Vally, 2014); ethnic clustering, urbanization and migration was investigated (van Leeuwen, 2014).

\section{Resilience}

The concept of resilience has been the focus of increasing significance for a broad range of researchers and practitioners. A generic definition of resilience as an ability to recover from or adjust to misfortune or change is provided by Merriam and Webster (2012).

A more academic definition delineates resilience as the processes occurring when environmental social or individual factors interrupt the trajectory of moving from risk to pathology. The variables contributing to these resilience processes may be termed promotive factors since the emphasis is on a strengthbased approach to developing positive interactions (Zimmerman et al, 2002). 
Three basic promotive models are proposed: (1) compensatory-promotive factors counteract exposure to risk through opposite and direct effects; (2) protective-promotive factors counteract exposure to risk through opposite and direct effects; and (3) challenge-utilizes a type of inoculation, i.e. intentional exposure to controlled risk to develop resilience to reduce subsequent pathology development (Luthar, 2006; Masten, 2014; Masten et al 2007; Zimmerman et al, 2002).

The concepts and applications of resiliency theories have been investigated by a broad range of professionals including social theorists and crisis management personnel and have produced a wide range of reports: effects of early intervention on long-term development (Masten, 1994; 2014); importance of mentoring relationships (Zimmerman et al, 2013); responses to discrimination stress across ethnic stages of development (Romero et al, 2014); personal resilience in crisis situations with particular focus on methodologies for examining subjective well-being (Cummins, $\&$ Wooden, 2014); and motivations, management and mastery in processes related to resilience to the physical, psychological and social challenges of acute, chronic illness (DeSantis et al, 2013). Relevant studies note the importance of positive role models in the development of resilience.

The applications of the resilience concept in areas other than individual coping processes are illustrated by: role of resiliency in coping with international crime and terrorism as global threats (Bakker et al, 2012); examination of relationships to social ecology (Unger, 2011); inter-relationships of well-being and resilience in the context of human ecology (Armitage et all, 2012); resilience as part of urban planning (Desouza, \& Flannery, 2013); resilience within the context of social theory (Cote, \& Nightingale, 2012); interpersonal perspectives with examination of the social correlates of optimism (Smith et all, 2013); community resilience relationship to decision theory in response to catastrophic events (Cox, 2012); role of resilience in economic planning (Rose, 2007; Coaffee, 2008); role of economic resilience (Cachinho, 2014); and a model for organizational resilience (Cobb, \& Thampson, 2012).

Sage (2014) investigated the relationships between food sovereignty and the fostering of local resilience through local food production. It was proposed that the synergies involved constitute a vital element of civil mobilization and international solidarity. A relationship to global coalition building to combat the negative effects of corporate agri-food entities is specified.

The wide range of applications of the principles of resilience to human and social processes, challenges and problems was extended to the relationship between science and technology and creative resilience in responding to crisis 
situations (Cha, 2014); social resilience under the protracted stress of crisis (Gal, 2014); the relationship between vulnerability and resilience in disaster response situations when strong local relationships and social networks reduced vulnerability (Usamah et al, 2014).

Resilience processes are not limited to an age cohort and are not restricted to crisis management. Life conditions such, as racial or ethnic discrimination, social exclusion and poverty require high levels of resilience and sustained coping ability on the part of the affected individuals. Thus resilience may be viewed as a critical requirement for development of self-determination, civic participation and social inclusion. Research suggests that to be empowered, one must be resilient. This resilience must be supported by mutual values and goals among individuals with personal and social challenges and the array of potential service and support entities. This mutuality and solidarity should be impelled by moral and ethical benevolence, which respects human values and individual rights.

Both the diversity and depth of the sustained philosophical inquiry and research document the importance of the fundamental principles of benevolence, resilience and solidarity to addressing the challenges and issues inherent in social change processes and personal needs. They are not recondite artifacts of only historical interest but can represent a dynamic framework for response to current social developments and conditions. Benevolence with its caring, compassion and empathy which respects the dignity and rights of all concerned; resilience with its foundation for coping and self-determination within social processes and networks; and solidarity with its base for synergy, reciprocity, cooperation, social networking and collective action form a triangle (framework) of supports and guidance to efforts to enhance the capabilities of marginalized or threatened people to achieve a positive quality of life with social inclusion. These values and principles apply to the responses to crises or disasters (whether natural or man-made), long-term challenges (e.g., racism, discrimination, poverty), and to areas of individual problems such as disabilities and acute chronic illness.

The objective is to test, in an exploratory approach, the existence of empirical relationships among these three concepts. We hypothesized that these relations adopt an explanatory sequence, going from the most fundamental frames (values) that give shape to social networks, which finally may facilitate improved resilience.

\section{THE MODEL: CONCEPTUAL FRAMEWORK AND MEASUREMENT}

These three concepts, benevolence, solidarity in action and resilience are considered firstly from a hierarchical point of view as a first step. Benevolence 
expresses values that orient individuals towards some lines of actions. These actions include giving support to and receiving support from others. We can consider these actions of giving and receiving support as dimensions of solidarity. Thus, solidarity refers to social networks and interpersonal ties. A person may or may not participate in these solidarity networks. From a sociological approach, we are considering how values frame the social culture and their effects on interpersonal relationships. This has been a classical approach since the XIX century, and clearly refers to authors such as Max Weber. Secondly, we consider how the concept of resilience may be dependent on the solidarity networks. Again, considerations of social ties and their positive effects on individuals recovering from crisis is presented in such works as "The suicide" from Emile Durkheim. Consequently, it may be possible to assess the effects of social ties (giving and receiving support) by how easily individuals report that they recover from crisis. In a sense, this is a hypothesis in close relation with anomy.

The logical explanatory sequence goes from general to particular. This idea means that starting from values we explain social interactions and, from social interactions we explain the resilience, measured at an individual level. In this sense, even if resilience is measured at individual level, we are in fact considering "resilience" as a feature of the social system. If we propose the effect from interactions in resilience, we are not focusing on a personality trait. We are proposing, from Durkheim's point of view, that some dimensions of social interactions (close ties) are associated with a higher presence of resilience, at a societal level.

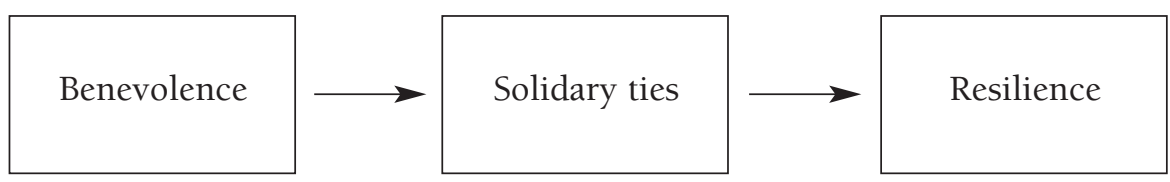

Extant data are not specific to testing the effects of benevolence values in social networks (supportive ties) and, indirectly, on the resilience capacity of individuals. In the case of the ESS W6 (2012) there are some variables that allow us to test the former model. These analyses must consider that these measurements are optimized in the context of different scales. The concept of "Benevolence" is measured in the "Human Values Scale" from Schwartz. The variables measuring "Solidary ties" and "Resilience" belong to the "Subjective wellbeing scale" (SWB). For this reason, the operational approach (wording or measurement) is different in both scales. This is a difficulty that has to be considered when establishing the empirical fit of the model. 


\section{DATA AND HYPOTHESIS}

The currently proposed model(s) utilize data from the European Social Survey (ESS) W6.2 (2012). Benevolence relates to the Human Values Scale. Schwartz defines benevolence as the "preservation and enhancement of the welfare of people with whom one is in frequent personal contact." The adjectives linked with these concepts are "helpful, honest, for giving, loyal or responsible". This way, the dimension "Benevolence" is measured with two indicators:

a) "It's very important to him to help the people around him. He wants to care for other People"

b) "It is important to him to be loyal to his friends. He wants to devote himself to people close to him."

Data regarding those variables have been recorded to give the lowest value (1) to the category "Not very much like me" and the highest (6) "Very much like me". Subsequently, we tested their reliability (Cronbach alpha) and summed the two items (Likert approach).

There are wide variations in the alpha values when considering the 29 countries of the ESS. For some of them the alpha values are really low (around .65) and for others are reasonable, close to .80. For this reason we take this analysis as an exploratory approach: the measurement has not been optimized if we take into account the diversities of cultures and traditions. This is a usual pitfall in comparative analysis. The consequences are obvious. The measurement of the "benevolence" (as a cluster of values) contains errors that may affect its relations with other variables. From an empirical approach, they may weaken their relations or, in the worst, these errors may correlate with the measurement errors of the dependent variables (supportive actions and recover from crisis). As we will check, there is no empirical evidence of covariation among the errors when fitting the structural models. The new scale run from 1 to 12 , where 1 is a low score on benevolence and 12 is a high one.

The measurements of "Solidarity by ties" and "Resilience" belong to the measurement of "Subjective well being scale" module ${ }^{3}$. The authors (Huppert et al) define resilience in the following way.

"Resilience generally refers to positive adaptation in the context of risk or adversity. It is a broad concept that encompasses a wide range of phenomena, including

\footnotetext{
2 "Very much like me", "Like me", "Somewhat like me", "A little like me", "Not like me", "Not like me at all"

${ }^{3}$ ESS. Round 6. Question Module Design. Final Template. Personal and social well-being. Module Authors: Felicia Huppert, Nic Marks, Juliet Michaelson, Carmelo Vázquez and Joar Vitters.
} 
the capacity of a system to adapt or recover from significant challenges. Rather than a personality trait (i.e., resiliency), resilience describes the ability to sustain adaptive functioning under difficult circumstances. In all these cases, resilience refers to patterns of doing well after exposure to a serious adversity or threat. Resilience research has focused on two distinct situations. A) stress resistance and B) bouncing-back". (Page 11)

We have focused on the concept, in our opinion, which is closest to the idea of resilience: the speed of recovery. For that reason, in this research we have used the notion of "Bouncing back" that "Refers to returning to, and speed of return to, a previous level of good functioning following difficult times or severely disturbing experiences." (Page 12). The measurement of Resilience is operationalized in the following way: "When things go wrong in my life it takes a long time to get back to normal". The scale has been recoded into a balance variable where the codes (1) "Agree strongly", and (2) "Agree" are recoded (-1), code (3) "Neither agree nor disagree" recoded (0), and codes (4) "Disagree" and (5) "Disagree strongly" recoded (1). Negative values referred to difficulties to recover from crisis while positive sign identify those who recover easily from crisis. The value (0) identifies those who feel neutrals in relation with the idea of recovering from a crisis.

One of the dimensions of solidarity is the concept of interpersonal relations. Social networks and social relations are fundamental for social and individual wellbeing. In this particular case, we refer to the measurement of solidarity offered by the ESS, as "solidarity by social tie". This is considered appropriate because "Solidarity" is defined by the sub concept based on social interactions, which is defined by supportive actions with people close to the individual. From the approach of the developers of the module, they consider essentially the thick or thin nature of the network. They define "thick relationships" as

"Measures of thick relationships capture the quality of 'bonding ties' that is, of relationships to individuals you know well and the people closest to you, i.e. close family and friends. It is a core part of the social element of good functioning. It covers having sources of support from others, feeling appreciated by people close to you and spending enjoyable time with them." In this context, is defined the following sub concept. The sub concept "Reciprocity in social Exchange" refers to

"A balance between give and take in relevant social relationships (social reciprocity) is a universal principle guaranteeing stability and justice of social exchange. The recurrent experience of reciprocity has significant impact on social well-being,

4 "Agree Strongly", "Agree”, "Neither agree nor disagree”, "Disagree”, "Disagree strongly" 
while failed reciprocity elicits strong negative emotions and bodily stress reactions. Reciprocity in social exchange is measured here in relation to thick relationships, i.e. people who respondents feel close to: perception of support from and feeling appreciated by those one is close to and providing help and support to them in turn". (Page 26).

In this case, the wording of the measurements asks for the "both sides story". This approach means to give and receive support. "And to what extent do you provide help and support to people you are close to when they need it?", "And to what extent do you provide help and support to people you are close to when they need it?" The concept "help and support" is "whether emotional or material". At the same time, "close to" in the sense of "emotionally close" rather than "physically close". The scale for both measurements goes from none (0) to completely (6). We have considered again a Likert scale, and we proceed in the same way than with the measurement of Benevolence. The alpha coefficient shows a shorter range of variations across the 29 countries, being more conclusive about the additive nature of the scale. In this sense, we produce a new scale by adding the two approaches: give and receive. This scale range from 0 to 12 , and give higher score to those individuals who are more supportive.

The models tested used data specific to variables defined in different theoretical frameworks. In this sense, the meaning and purpose of the measurement was retained, but adapted to an explicative model. In short, the measurement models were adapted to fit a new set of hypotheses. The theoretical model posited that the values of "Benevolence" influence the "Supportive ties" and the "Resilience". This influence may be exerted in two different ways. The first model states three hypotheses. That a) Benevolence values influence the supportive action in solidarity networks and b) Benevolence affects the levels in individual resilience. These mean that the presence of Benevolence values is related with supportive actions, and with a higher probability to recover from difficulties. The hypothesis c) proposes that solidarity is related with individual resilience. Those that are more supportive in interpersonal relations recover more easily from difficulties. As a model, the idea is that Benevolence values have a direct effect on Resilience and an indirect effect by the variable Solidarity. Solidarity may have a direct effect on Resilience.

In the first model, the benevolence values is a factor that improve individual resilience directly, suggesting that people with these values are more probable to recover from crisis, and also indirectly through the influence of belonging to supportive networks. There is also a direct effect from belonging to supportive networks in resilience. 


\section{Model 1. Direct and indirect effect of Benevolence}

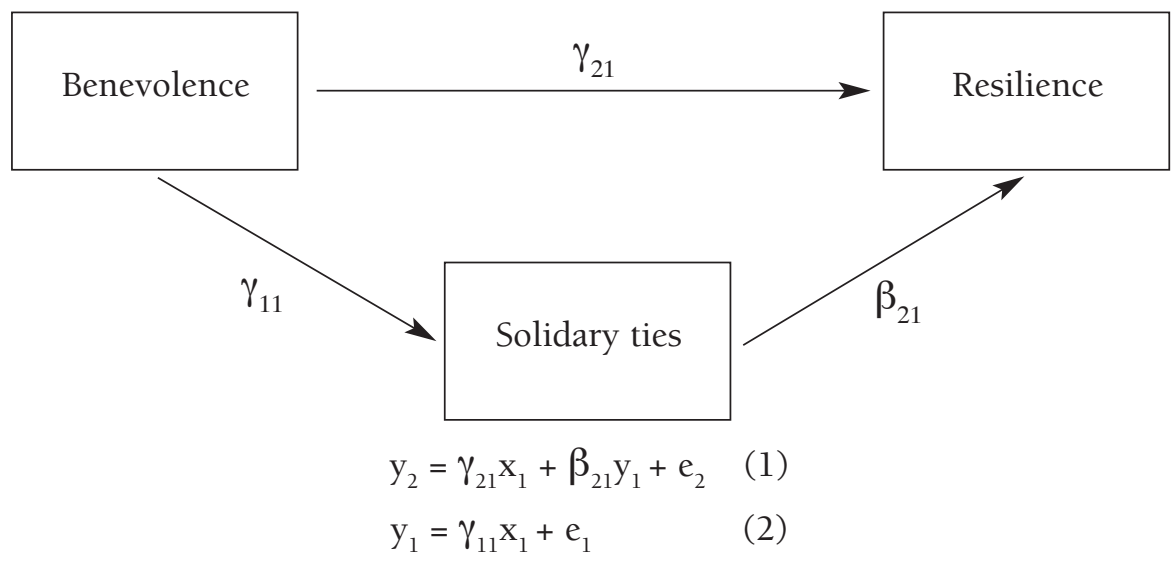

standing $\mathrm{x}_{1}$ for Benevolence, $\mathrm{y}_{1}$ for Solidarity and $\mathrm{y}_{2}$ for Resilience.

The second model contains two basic hypotheses, and is a sub model of the first one. The first hypothesis a) Benevolence values influence the supportive actions in solidarity networks, and the second b) that solidarity is related with individual resilience. As a model, the idea is that Benevolence values have a direct effect on Solidarity, and an indirect effect on Resilience through the variable Solidarity. The second model is a clearly one-way, hierarchical model, where the benevolence values have an indirect effect trough the supportive network. The presence of benevolence values increases the probability to participate in supportive network and this activity increases the individual resilience.

\section{Model 2. Indirect effect of Benevolence}

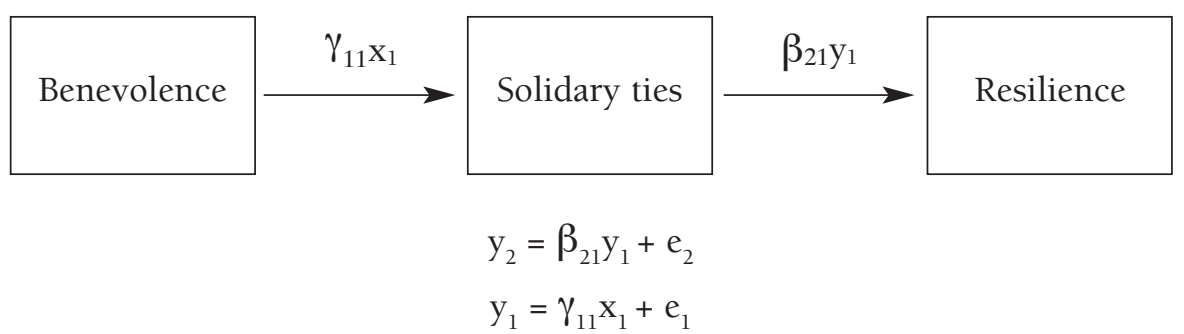

standing $\mathrm{x}_{1}$ for Benevolence, $\mathrm{y}_{1}$ for Solidarity and $\mathrm{y}_{2}$ for Resilience.

It is important to note that this is an exploratory analysis using secondary data. In many senses, the fit of the models is working in adverse conditions. The measurements of the concepts were developed following their own independent logic. This mean that the wording of the questions were tested without con- 
sider any consistence between Benevolence and the SWB scales. This is especially true because the "Human Values Scale" has its own method in the questions wording and the frame of the answers. Just because they coincide in the same questionnaire is what allow us to test these hypotheses. But in any case these hypotheses were not in the original purpose of the questionnaire.

\section{MODEL FITTING}

Using the data from 29 countries, we have applied the structural equations method to test the two models. The first one is clearly rejected. The t-test shows for all of them that the direct relation from "Benevolence" into "Resilience" became not significant when the variable "Solidarity by social ties" is included. This means that the direct relationship between "Benevolence" and "Resilience" is cancelled when controlled by "Solidarity".

However, the second model is significant. All the countries considered show an indirect effect from "Benevolence" in "Resilience", through the intermediate variable "Solidarity by ties". The table 1 shows the RMSA as an indicator of fit. We can appreciate that the RMSA is under 0.05 for 21 countries: Portugal, Sweden, Germany, France, Great Britain, Poland, Slovakia, Hungary, Denmark, Switzerland, Estonia, Finland, Kosovo, Belgium, Norway, Spain, Lithuania, Czech Republic, Russia, Bulgaria and Cyprus. This means that the model 2 has a good fit to data. At the same time, if we consider the $t$-values for all the coefficients, we can observe that they are significant. The coefficients are significantly different from cero and the null hypothesis may be rejected. There are a direct relation between "Benevolence" and "Solidarity by ties", and indirectly, a mediate effect from "Benevolence" in "Resilience".

Table 1. Fit of Model 2: RMSA $<0.05$

\begin{tabular}{|c|c|c|c|c|c|}
\hline Country & & $\gamma_{11}$ & $\beta_{21}$ & RMSA & (n) \\
\hline \multirow{3}{*}{ Portugal } & Raw Coefficient & 0.41 & 0.05 & \multirow{3}{*}{0.00} & \multirow{3}{*}{2070} \\
\hline & Standardized & 0.31 & 0.12 & & \\
\hline & $\mathrm{t}$ value & 14.8 & 5.6 & & \\
\hline \multirow{3}{*}{ Sweden } & Raw Coefficient & 0.34 & 0.06 & \multirow{3}{*}{0.00} & \multirow{3}{*}{1828} \\
\hline & Standardized & 0.31 & 0.14 & & \\
\hline & t value & 14.1 & 5.9 & & \\
\hline \multirow{3}{*}{ Germany } & Raw Coefficient & 0.40 & 0.06 & \multirow{3}{*}{0.00} & \multirow{3}{*}{2914} \\
\hline & Standardized & 0.32 & 0.11 & & \\
\hline & $\mathrm{t}$ value & 17.9 & 6.2 & & \\
\hline
\end{tabular}




\begin{tabular}{|c|c|c|c|c|c|}
\hline Country & & $\gamma_{11}$ & $\beta_{21}$ & RMSA & (n) \\
\hline \multirow{3}{*}{ France } & Raw Coefficient & 0.25 & 0.04 & \multirow{3}{*}{0.00} & \multirow{3}{*}{1890} \\
\hline & Standardized & 0.23 & 0.08 & & \\
\hline & $\mathrm{t}$ value & 10.1 & 4.4 & & \\
\hline \multirow{3}{*}{ Great Britain } & Raw Coefficient & 0.28 & 0.06 & \multirow{3}{*}{0.00} & \multirow{3}{*}{2238} \\
\hline & Standardized & 0.24 & 0.11 & & \\
\hline & t value & 11.5 & 5.4 & & \\
\hline \multirow{3}{*}{ Poland } & Raw Coefficient & 0.34 & 0.06 & \multirow{3}{*}{0.00} & \multirow{3}{*}{1824} \\
\hline & Standardized & 0.25 & 0.13 & & \\
\hline & \begin{tabular}{|l}
$\mathrm{t}$ value \\
\end{tabular} & 10.9 & 5.5 & & \\
\hline \multirow{3}{*}{ Slovakia } & Raw Coefficient & 0.34 & 0.10 & \multirow{3}{*}{0.00} & \multirow{3}{*}{1774} \\
\hline & Standardized & 0.28 & 0.22 & & \\
\hline & t value & 12 & 9.7 & & \\
\hline \multirow{3}{*}{ Hungary } & Raw Coefficient & 0.31 & 0.08 & \multirow{3}{*}{0.00} & \multirow{3}{*}{1927} \\
\hline & Standardized & 0.24 & 0.22 & & \\
\hline & t value & 11 & 9.7 & & \\
\hline \multirow{3}{*}{ Denmark } & Raw Coefficient & 0.35 & 0.06 & \multirow{3}{*}{0.00} & \multirow{3}{*}{1598} \\
\hline & Standardized & 0.28 & 0.14 & & \\
\hline & t value & 11.8 & 5.5 & & \\
\hline \multirow{3}{*}{ Switzerland } & Raw Coefficient & 0.36 & 0.07 & \multirow{3}{*}{0.00} & \multirow{3}{*}{1478} \\
\hline & Standardized & 0.28 & 0.13 & & \\
\hline & $\mathrm{t}$ value & 11.1 & 5.0 & & \\
\hline \multirow{3}{*}{ Estonia } & Raw Coefficient & 0.41 & 0.06 & \multirow{3}{*}{0.00} & \multirow{3}{*}{2298} \\
\hline & Standardized & 0.26 & 0.16 & & \\
\hline & t value & 13.07 & 7.53 & & \\
\hline \multirow{3}{*}{ Finland } & Raw Coefficient & 0.33 & 0.04 & \multirow{3}{*}{0.00} & \multirow{3}{*}{2145} \\
\hline & Standardized & 0.29 & 0.09 & & \\
\hline & t value & 13.8 & 4.04 & & \\
\hline \multirow{3}{*}{ Kosovo } & Raw Coefficient & 0.25 & 0.07 & \multirow{3}{*}{0.00} & \multirow{3}{*}{1205} \\
\hline & Standardized & 0.14 & 0.17 & & \\
\hline & t value & 5.0 & 5.8 & & \\
\hline
\end{tabular}




\begin{tabular}{|c|c|c|c|c|c|}
\hline Country & & $\gamma_{11}$ & $\beta_{21}$ & RMSA & (n) \\
\hline \multirow{3}{*}{ Belgium } & Raw Coefficient & 0.39 & 0.05 & \multirow{3}{*}{0.01} & \multirow{3}{*}{1857} \\
\hline & Standardized & 0.25 & 0.12 & & \\
\hline & t value & 10.9 & 5.3 & & \\
\hline \multirow{3}{*}{ Norway } & Raw Coefficient & 0.23 & 0.05 & \multirow{3}{*}{0.02} & \multirow{3}{*}{1599} \\
\hline & Standardized & 0.22 & 0.12 & & \\
\hline & t value & 8.8 & 5.0 & & \\
\hline \multirow{3}{*}{ Spain } & Raw Coefficient & 0.35 & 0.06 & \multirow{3}{*}{0.03} & \multirow{3}{*}{1762} \\
\hline & Standardized & 0.25 & 0.12 & & \\
\hline & t value & 10.7 & 5.0 & & \\
\hline \multirow{3}{*}{ Lithuania } & Raw Coefficient & 0.23 & 0.09 & \multirow{3}{*}{0.03} & \multirow{3}{*}{2035} \\
\hline & Standardized & 0.20 & 0.24 & & \\
\hline & t value & 9.38 & 11.04 & & \\
\hline \multirow{3}{*}{ Czech Republi } & Raw Coefficient & 0.43 & 0.08 & \multirow{3}{*}{0.04} & \multirow{3}{*}{1905} \\
\hline & Standardized & 0.38 & 0.20 & & \\
\hline & t value & 17.7 & 8.9 & & \\
\hline \multirow{3}{*}{ Russia } & Raw Coefficient & 0.28 & 0.06 & \multirow{3}{*}{0.04} & \multirow{3}{*}{2371} \\
\hline & Standardized & 0.22 & 0.18 & & \\
\hline & t value & 11.1 & 8.9 & & \\
\hline \multirow{3}{*}{ Bulgaria } & Raw Coefficient & 0.45 & 0.09 & \multirow{3}{*}{0.04} & \multirow{3}{*}{2142} \\
\hline & Standardized & 0.33 & 0.23 & & \\
\hline & t value & 16 & 11.1 & & \\
\hline \multirow{3}{*}{ Cyprus } & Raw Coefficient & 0.35 & 0.03 & \multirow{3}{*}{0.04} & \multirow{3}{*}{1103} \\
\hline & Standardized & 0.22 & 0.06 & & \\
\hline & t value & 7.5 & 2.07 & & \\
\hline
\end{tabular}

Source: authors analysis of ESS W6 data

There are six other countries with low, but for many authors still significant, RMSA. Those countries are Netherlands, Ukraine, Iceland, Israel, Slovenia and Ireland. In all these countries the t-values are also significant in all the cases. 
Table 2. Fit of Model 2: RMSA $\leq 0.09$

\begin{tabular}{|c|c|c|c|c|c|}
\hline Country & & $\gamma_{11}$ & $\beta_{21}$ & RMSA & (n) \\
\hline \multirow{3}{*}{ Netherlands } & Raw Coefficient & 0.18 & 0.04 & \multirow{3}{*}{0.06} & \multirow{3}{*}{1108} \\
\hline & Standardized & 0.15 & 0.09 & & \\
\hline & $\mathrm{t}$ value & 5.02 & 2.98 & & \\
\hline \multirow{3}{*}{ Ukraine } & Raw Coefficient & 0.25 & 0.05 & \multirow{3}{*}{0.06} & \multirow{3}{*}{1971} \\
\hline & Standardized & 0.24 & 0.13 & & \\
\hline & t value & 10.9 & 5.8 & & \\
\hline \multirow{3}{*}{ Iceland } & Raw Coefficient & 0.22 & 0.05 & \multirow{3}{*}{0.07} & \multirow{3}{*}{720} \\
\hline & Standardized & 0.21 & 0.10 & & \\
\hline & $\mathrm{t}$ value & 5.7 & 2.6 & & \\
\hline \multirow{3}{*}{ Israel } & Raw Coefficient & 0.20 & 0.11 & \multirow{3}{*}{0.08} & \multirow{3}{*}{2268} \\
\hline & Standardized & 0.17 & 0.27 & & \\
\hline & t value & 8.26 & 13.27 & & \\
\hline \multirow{3}{*}{ Slovenia } & Raw Coefficient & 0.38 & 0.08 & \multirow{3}{*}{0.08} & \multirow{3}{*}{1223} \\
\hline & Standardized & 0.29 & 0.18 & & \\
\hline & t value & 10.7 & 6.3 & & \\
\hline \multirow{3}{*}{ Ireland } & Raw Coefficient & 0.45 & 0.07 & \multirow{3}{*}{0.09} & \multirow{3}{*}{2545} \\
\hline & Standardized & 0.34 & 0.18 & & \\
\hline & $\mathrm{t}$ value & 18.3 & 9.4 & & \\
\hline
\end{tabular}

Source: authors analysis of ESS W6 data 2012

Finally, there are two countries Albania and Italy, that have RMSA of 0.00 but their t-values (relation from "Benevolence" in "Solidarity") are not significant. The main reason for this low t-value in the relation from "Benevolence" in "Solidarity" is the sample size.

\section{DISCUSSION}

Some basic considerations are posed in relation with the results of the analyses. The first is relates to the two essential concepts underlying this research. From a theoretical point of view, the idea of values giving shape to social structure, and the social structure as a factor that influence the anomie or social integration is well founded. To debate about this idea we would need to consider almost all 
the sociological thinking. But it is difficult to find empirical research oriented to test these three fundamental relationships. In this sense, from the empirical approach, this analysis is really an exploratory analysis. This exploratory soul has to deal with several severe limitations.

One of these limitations relates to the origin of the data. European Social Survey data were used for secondary data analysis. In this context, the models tested are conditioned by the original purpose of the measurement procedures. In other words, the measurements have not been defined in order to test these set of hypotheses. The measurement of the Human Value Scale has their idiosyncrasy. In a sense, is more oriented to fulfill and validate its own proposal about the value structure than being friendly with other social and cultural dimensions. We are speaking about the cognitive focus of the measurement operationalizations, but also about the procedures of standardization of the scales. The same can be said about the SWB scale. In this ESS 2012 we find the second try of this model for measure the wellbeing from a psychological approach (subjective). The first concern is the applicability of a psychological scale, in the framework of a social survey. The documents show a great methodological effort to adjust the meaning and the operationalizations, but the limitations of the psychological approaches are clear. The personal and sensitive topics are always a problem difficult to solve, essentially, because the framing effects of the "tool" (survey questionnaire) and the effects of the position in the flow of the interview. The second concern refers to the same question related to the Human Value Scale. The operationalization of the concepts, and sub concepts, Solidarity and Resilience, are oriented to themselves. They are not designed to be a part of an argument or explanation. This limitation is habitual when a researcher is working with secondary data. In this case, the measurements follow their own operational logic without considering being part of a global argument. Even if the measurement of each concept be valid and reliable, they are not design to fit each other in an explanation.

In this context, the models tested are conditioned by the original purpose of the measurement procedures. The measurements have not been defined in order to test these set of hypotheses. At the same time, another important point is that the models are tested in 29 countries. All the problems that emerge in comparative analysis are there to be added to this exploratory research. Notably, even in this adverse situation, the models, considering the 29 countries under study, behave fairly well.

Twenty one countries obtained a low RMSA (under 0.05), and significant $\mathrm{t}$-values in the two effects considered $\gamma 11$ and $\beta 21$. The twenty-one models even in adverse conditions and from an exploratory approach, show significant fits. 
Another six countries have also a significant RMSA, five of them $\leq .08$ and one $\leq .09$ (Ireland). The t-values for the two effects considered in the model are also statistically significant. Finally, there are two countries, Albania and Italy, where the problems come clearly from the sample size. Their RMSA coefficients are significant $<.00$, but the t-value in the effect $\gamma 11$ is not statistically significant. For example, only a small increase in the sample size results in a significant t-value.

After investigating the two models under consideration, a clear summary conclusion appears warranted. The model that proposed a direct effect from Benevolence in Resilience does not hold when controlling for Solidary-ties. The best explanation affirms that the values of "Benevolence" have an indirect effect in "Resilience". This effect is mediated by the supportive actions of the individuals. In summary, Benevolence values explain the probability to participate in supportive relations, and this social network (based in solidarity ties) is related with a better recovery from crisis and adversities. This model is consistent with the sociological and psychological theories more consolidated. In that sense, we may say that the values of "Benevolence", working through the supportive network, or "Solidarity by ties", help people to activate "Resilience". As we said, this is consistent with the sociological theory. For example, E. Durkheim in his classical research, "The suicide", explains how social network and personal ties help people to avoid isolation, anomie and finally to commit suicide. More recently Putnam also refers to social ties as a social capital that helps people to promote in their lives. This author emphasized especially the belonging to associations and other organizations. In this analysis we consider the interpersonal ties, as a supportive social network, which shows a clear effect on the ability to recover from crisis, considering a societal perspective.

The conclusions from the analysis are interesting. First, the structures of effects, from cultural values to social network, and from social network in resilience are consistent in the 29 countries. There are some minor discrepancies that may be attributed to the high quantity of tests (29), the sample size of some countries or the different cognitive approaches to the questions wording in different scales. In any case, is clear that more research is needed to increase the empirical support to this classical explanation. But, to the moment, the evidences show that the structure of the model is consistent in the majority of the countries considered. To say it shortly, the resilience that shows a society is partly a consequence of the supportive networks that are shaped by the presence of benevolence values. 


\section{REFERENCES}

Alaminos, A. (2007) El análisis de la realidad social. Modelos estructurales de covarianzas. Alicante: OBETS

Alaminos, A. (2005) Socialización, ideología y participación: casos prácticos de análisis estructural de covarianzas. Alicante: OBETS.

Alaminos, A \& Santacreu, O. (2009) "Living across cultures in a transnational Europe" in Recchi, E and Favell, A. (ed.) Pioneers of European Integration. Massachusetts: Edward Elgar

Alaminos (2002) Maneras de vivir la sociedad en Europa. Madrid: Sistema.

Aretz, B. \& Kube, S. (2013). Choosing Your Object of Benevolence: A Field Experiment on Donation Options. Scandinavian Journal of Economics. 115(1), 62-73.

Armitage, D., Béné, C., Charles, A.T., Johnson D., \& Allison E.H. (2012). The Interplay of Well-being and Resilience in Applying a Social-Ecological Perspective. Resilience Alliance, Ecology and Society. 17 (4), 15. http://dx.doi.org/10.5 751/ES04940-170415. Retrieved on 20.05.2015.

Bakker, R.M., Raab, J., \& Milward, H.B. (2012). A Preliminary Theory of Dark Network Resilience. Journal of Policy Analysis and Management. 31(1), 33-62.

Bardi, A., Lee, J.A., Hoffmann-Towfigh, N., \& Soutar, G. (2009). The structure of intraindividual value change. Journal of Personality and Social Psychology. 97, 913-929.

Bauman, Z. (1993). Postmodern Ethics. Oxford: Blackwell Publishers.

Betz, H.G. \& Johnson, C. (2004). Against the current-stemming the tide: the nostalgic ideology of the contemporary radical populist right. Journal of Political Ideologies. 9(3), 311-327.

Brown, S.L., Nesse, R.M., Vinokur, A.D., \& Smith, D.M. (2003). Providing social support may be more beneficial than receiving it: results from a prospective study of mortality. Psychological Science, 14 (4), 320-327.

Brunkhorst, H. (2009). The Transformation of Solidarity and the Enduring Impact on Monotheism. Philosophy and Social Criticism. 35(1-2), 93-103.

Cachinho, H. (2014). Consumers capes and the resilience assessment of urban retail systems. Cities. 36, 131-144.

Carpenter, A. (2014). Resilience in the social and physical realms: Lessons from the Gulf Coast. International Journal of Disaster Risk Reduction. 35(3), 266-279.

Cha, I. (2014). Subjectivity and Solidarity - a Rebirth of Humanism. Diogenes. 60(1), 2126.

Coaffee, J. (2008). Risk, resilience, and environmentally sustainable cities. Energy Policy. 36, 4633-4638.

Cobb, A.N., \& Thampson, J.L. (2012). Climate change scenario planning: A model for the integration of science and management in environmental decision-making. Environmental Modelling \& Software. 38, 296-305. 
Cote, M., \& Nightingale, A.J. (2012). Resilience thinking meets social theory: Situating social change in socio-ecological systems (SES) research. Progress in Human Geography. 36(4), 475-489.

Cox, Jr. L.A. (2012). Community Resilience and Decision Theory Challenges for Catastrophic Events. Risk Analysis. 32(11), 1919-134.

Cummins, R.A., \& Wooden M. (2014). Personal Resilience in Times of Crisis: The Implications of SWB Homeostasis and Set-Points. Journal of Happiness Studies. 15, 223-235.

DeSantis J.P., Florom-Smith, A., Vermeesch, A., Barroso, S., \& DeLeon D.A. (2013). Motivation, Management, and Mastery: A Theory of Resilience in the Context of HIV Infection. Journal of the American Psychiatric Nurses Association. 19(1), 36-46.

Desouza, K.C., \& Flannery, T.H. (2013). Designing, planning, and managing resilient cities: A conceptual framework. Cities, 35, 89-99.

Diener, E., \& Seligman, M.E.P. (2002). Very happy people. Psychological Science. 13, 81-84.

Dunn, E.W., Aknin, L.B., \& Norton, M.I. (2008). Spending money on others promotes happiness. Science. 319, 1687-1688.

European Social Survey Round 6 Data (2012). Data file edition 2.1. Norwegian Social Science Data Services, Norway - Data Archive and distributor of ESS data.

ESS Round 6: European Social Survey (2014): ESS-6 2012 Documentation Report. Edition 2.1. Bergen, European

Eyre, D. \& Littleton J. (2012). Shaping the Zeitgeist: Influencing Social Processes as the Center of Gravity for Strategic Communications in the Twenty-first Century. Public Relations Review. 38, 179-187.

Firat, R. (2014). Media Usage and Civic Life: The Role of Values. Journal of Social and Political Psychology. 2(1), 117-142.

Forno, F. \& Graziano, P. (2014). Sustainable Community Movement Organisations. Journal of Consumer Culture. 14(2), 139-157.

Gal, R. (2014). Social Resilience in Times of Protracted Crises: An Israeli Case Study. Armed Forces and Society. 40(3), 475-452.

Gallagher, A. (2013). Solidarity and Moral Perception. Nursing Ethics. 20(5), 499-500.

Hauswald, H. \& Hack, A. (2013). Impact of Family Control/Influence on Stakeholders' Perceptions of Benevolence. Family Business Review. 26(4), 356-373.

Helliwell, J., \& Putnam, R.D. (2005). The social context of well-being. In F.A. Huppert, B. Keverne, \& N. Baylis (Eds.) The Science of Well-being Oxford: Oxford University Press, 435-459.

Hlatshwayo, M. \& Vally, S. (2014). Violence, Resilience and Solidarity: The Right to Education for Child Migrants in South Africa. School Psychology International. 35(3), 266-279.

Hodgkin, S. (2014). Intergenerational Solidarity: An Investigation of Attitudes Towards the Responsibility for Formal and Informal Elder Care in Austrailia. Health Sociology Review. 23(1), 53-64. 
Hövermann A., Groß E.M., Zick A., Messner S.F. (2015). Understanding the devaluation of vulnerable groups: A novel application of Institutional Anomie Theory. Social Science Research. 52, 408-421.

Houtepen, R. \& Ter Meulen, R. (2000). New types of solidarity in the European Welfare State. Health Care Analysis. 8(4), 329-340.

Huppert, F. Marks, N., Michaelson, J., Vázquez C., Vittersø, J. (2013). European Social Survey (2013) Round 6 Module on Personal and Social Wellbeing - Final Module in Template. London: Centre for Comparative Social Surveys, City University London.

Kapeller, J. \& Wolkenstein, F. (2013). The Grounds of Solidarity: From Liberty to Loyalty. European Journal of Social Theory. 16(4), 476-491.

Knight, L. (1997). Benevolence and Justice in Jane Adam's "A Modern Lear". Journal of Women's History. 9(1), 111-138.

Levine, E. \& Schweitzer, M. (2014). Are Liars Ethical: On the Tension Between Benevolence and Honesty. Journal of Experimental Social Psychology. 53, 107-117.

Luthar, S.S. (2006). Resilience in development: A synthesis of research across five decades. In D. Cicchetti \& D. J. Cohen (Eds.), Developmental psychopathology. Vol. 3. Risk, disorder, and adaptation (2 ${ }^{\text {nd }}$ ed.). Hoboken, NJ: Wiley, 739-795.

Malsch, B. (2013). Politicizing the Expertise of the Accounting Industry in the Realm of Corporate Social Responsibility. Accounting Organizations and Society. 38, 149-168.

Masten, A.S. (1994). Resilience in individual development: Successful adaptation despite risk and adversity. In M. Wang \& E. Gordon (Eds.), Risk and resilience in inner city America: Challenges and prospects ( $2^{\text {nd }}$ Ed.). Hillsdale, NJ: Erlbaum, 3-25.

Masten, A.S., (2014). Invited Commentary: Resilience and Positive Youth Development Frameworks in Developmental Science. Journal of Youth Adolescence. 43, 1018-1024.

Masten, A.S., Cutuli, J.J., Herbers, J.E., \& Reed, J.M.-G. (2007). Resilience in development. In S.J. Lopez \& C. R. Snyder (Eds.), The Oxford handbook of positive psychology Oxford, England: Oxford University Press, 117-131.

Merriam-Webster. (2012). Retrieved May, 2015, from http://www.merriam-webster.com.

Paxton, P. (1999). Is social capital declining in the United States? A multiple indicator assessment. American Journal of Sociology. 105(1), 88-127.

Paxton, P. (2002). Social capital and democracy: An interdependent relationship. American Sociological Review. 67(2), 254-277.

Putnam, R. (1994). Making Democracy Work: Civic Traditions in Modern Italy. Princeton, NJ: Princeton University Press.

Putnam, R.D. (1995). Bowling alone: America's declining social capital. Journal of Democracy. 6, 65-78.

Putnam, R.D. (2000). Bowling alone. NY: Simon, \& Schuster.

Quintelier, E. (2007). Differences in political participation between young and old people. Contemporary Politics. 13(2), 165-180.

Rock, M. \& Degeling, C. (2015). Public Health Ethics and More-than-human Solidarity. Social Science and Medicine. 129, 61-67. 
Romero A.J., Edwards, L.M., Fryberg, S.A., \& Orduña, M. (2014). Resilience to discrimination stress across ethnic identity stages of development. Journal of Applied Social Psychology. 44, 1-11.

Rose, A. (2007). Economic resilience to natural and man-made disasters: multi- disciplinary origins and contextual dimensions. Environmental Hazards. 7, 383-398.

Sage, C. (2014). The Transition Movement and Food Sovereignty: From Local Resilience to Global Engagement in Food System Transformation. Journal of Consumer Culture. 14(2), 254-275.

Schwartz, S.H. (1992). Universals in the content and structure of values: theoretical advances and empirical tests in 20 countries. In M. Zanna (Ed.), Advances in experimental social psychology. San Diego: Academic Press.

Schroeder, R. \& Ling, R., (2014). Durkheim and Weber on the Social Implications of New Information and Communication Technologies. New Media Society. 16(6), 789-805.

Schwartz, S.H., \& Bardi, A. (2001). Value hierarchies across cultures: taking a similarities perspective. Journal of Cross-Cultural Psychology, 32, 268-290.

Smith, A. (1982). Lectures on Jurisprudence, Edited by R.L. Meek, D.D. Raphael and P.G. Stein, Liberty Classics, Indianapolis, Indiana.

Smith, T.W., Ruiz, J.M., Cundiff, J.M., Baron, K.G., \& Nealey-Moore J.B. (2013). Optimism and pessimism in social context: An interpersonal perspective on resilience and risk. Journal of Research in Personality. 47, 553-562.

Sortheix, F. \& Lonnqvist, J-E. (2014). Personal Value Priorities and Life Satisfaction in Europe: The Moderating Role of Socioeconomic Development. Journal of Cross-Cultural Psychology. 45(2), 282-299.

Stevenson, N. (2006). European cosmopolitan solidarity: questions of citizenship, difference and post-materialism. European Journal of Social Theory. 9(4), 485-500.

Tulviste, T., \& A. (2014). Brief report: Value priorities of early adolescents. Journal of Adolescence. 37, 525-529.

Ungar, M. (2011). The Social Ecology of Resilience: Addressing Contextual and Cultural Ambiguity of a Nascent Construct. American Journal of Orthopsychiatry. 81(1), 1-17.

Usamah, M., Handmer, J., Mitchell, D., \& Ahmed, I. (2014). Can the Vulnerable be Resilient? Co-existence of Vulnerability and Disaster Resilience: Informal Settlements in the Philippines. International Journal of Disaster Risk Reduction. 10, 178-189.

Van Leeuwen, B. (2014). Urban Civility or Urban Community? A False Opposition in Richard Sennett's Conception. European Journal of Social Theory. 17(1), 3-23.

Van Oorschot, Arts, \& Gelissen, (2006). van Oorschot, W., Arts, W., \& Gelissen, J. (2006). Social capital in Europe: Measurement and social and regional distribution of a multifaceted phenomenon. Acta Sociologica, 49(2), 149-167.

Zimmerman, M.A., Bingenheimer, J.B., \& Notaro, P.C. (2002). Natural mentors and adolescent resiliency: A study with urban youth. American Journal of Community Psychology. 30, 221-243. 
Zimmerman, M.A., Stoddard, S.A., Eisman, A.B., Caldwell, C.H., Aiyer, S.M., \& Miller A. (2013). Adolescent Resilience: Promotive Factors That Inform Prevention. Child Development Perspectives. 7(4), 215-220.

IRINA L. PERVOVA has had academic appointments in St. Petersburg State University, Russia since 1994, and was promoted to the rank of Full Professor in 2006. Dr. Pervova was a research fellow of a number of Russian and International Scholars Programs, is the coordinator of research groups from Russia for two Marie Curie International Research grants is a member of St. Petersburg Filial of the Russian Children Fund, serves as an expert for the City Administration, chairs and organizes international conferences. Her academic service includes lecturing and graduate and PhD students advising. Dr. Pervova has been recognized by the Ministry of Education, Russian Federation with two honorary awards for excellence in professional achievement.

ANTONIO F. ALAMINOS has been researcher in several national and international research centers since 1987. Dr. Alaminos is Chair in Mathematical Sociology (promoted in 2000), and Head of the Department of Sociology II in the University of Alicante. Main lines of research are: methodology, empirical models, measurement (scales, indexes and systems of indicators), acculturation, comparative research, social movements, social mobility and political culture.

Recibido: 11/05/2015

Aceptado: 26/06/2015 